\title{
Modern Plastic Surgical Practice: Technical Competence Alone Is Not Enough
}

\author{
Ankur Khajuria ${ }^{1,2^{*}}$
}

1. Department of Surgery and Cancer, Imperial College London, UK;

2. Kellogg College, University of Oxford, UK
ABSTRACT

Annually, an estimated 234 million major surgical operations occur worldwide, with concomitant seven million complications and one million deaths. It is now well established that technical competence is necessary, but not sufficient for modern surgical practice and outcomes. Breakdown in non-technical skills has been attributed as a key root cause for near misses and patient harm in the operating room. This article discusses the multi-faceted skills-set that is necessary for the modern surgeon to succeed and for optimal patient outcomes. This includes technical skills, non-technical skills, with a focus on key CanMEDS framework domains, including leadership, communication, evidence-based surgery and mentorship.

\section{KEYWORDS}

Plastic surgery; Technical skills; Non-technical skills; Mentorship; Leadership

Please cite this paper as:

Khajuria A. Modern Plastic Surgical Practice: Technical Competence Alone Is Not Enough. World J Plast Surg 2020;9(2):119-127. doi: 10.29252/wips.9.2.119.

\section{INTRODUCTION}

Annually, an estimated 234 million major surgical operations occur worldwide, with concomitant seven million complications and one million deaths. ${ }^{1,2}$ It is now well established that technical competence is necessary, but not sufficient for modern surgical practice and outcomes. ${ }^{3-5}$ Breakdown in non-technical skills has been attributed as a key root cause for near misses and patient harm in the operating room. The complex inter-play between individual clinical skills, team factors and the clinical environment influences patient outcomes, as postulated by the systems approach. ${ }^{5}$

The CanMEDS clover, developed by Royal College of Physicians and Surgeons of Canada, is an educational framework that describes the key aptitudes underpinning the surgical expert. ${ }^{6}$ Both the profession and the general public expect to see these attributes in surgeons and these are widely accepted to lead to optimal healthcare and outcomes. ${ }^{6}$ This article will explore these aptitudes, and will discus both technical and non-technical skills. The non-technical skills section will begin with an overview followed by detailed discussion focusing on leadership (leader domain) and communication (communicator domain). Finally, evidence based surgery and mentorship (scholar domain) will be 
discussed as other key determinants of patient outcomes in surgery.

\section{TECHNICAL SKILLS}

Technical skills are an obvious prerequisite for good patient outcome. ${ }^{7}$ Indeed, Mahmoudi and colleagues showed that the risk of postoperative complications after free flap surgery was lower in high-volume and more experienced surgeons. ${ }^{8}$ The well-documented volume-outcome ratio provided further, emphasises the importance of technical skills with evidences supporting lower risk of operative death for patients treated at a high volume center. ${ }^{9}$

The lower mortality rate may, however, in part be explained by superior multidisciplinary care at the high volume centere and patient selection. ${ }^{10}$ The volume-outcome ratio has formed the basis of centralisation of surgical services for a variety of procedures. ${ }^{11}$ Technical skills learning has typically been delivered through an apprenticeship approach, whereby surgeons enhanced their skills through repeated practice on patients. ${ }^{12}$

The introduction of minimally invasive surgery was hailed as the "most dramatic change in surgery since the introduction of anaesthesia."13 It has now led to several procedures being performed exclusively by the laparoscopic approach, such as cholecystectomy. However, this is only when the early part of the learning curve had been taken into consideration. Early complications sparked doubts regarding the procedure's safety and this led to reconsideration of the training strategy. ${ }^{14}$

Skills courses were introduced for teaching basic psychomotor skills. As the number of surgeons performing the procedure increased, novice surgeons were then able to assist and learn. In Europe, the introduction of the European Working Time Directive (EWTD) with reduced training time,${ }^{15}$ combined with an unprecedented need for patient safety due to high profile cases ${ }^{3}$ meant that alternative training strategies had to be sought. The operating room was clearly not a safe environment for such experiential learning to occur. ${ }^{16}$

Simulation provides a viable and valid alternative for technical skill acquisition in a controlled, safe environment with no harm to the patient, especially at the early part of the learning curve. It allows proficiency based curricula to be delivered, enabling structured training in the form of knowledge base, task deconstruction, laboratory environment training and skills transfer, with valid and reliable measures of assessment. ${ }^{17,18}$

Indeed, simulation has been shown to shorten the learning curve and lead to a faster rate of technical skill acquisition. Moreover, simulation and structured curricula allow trainees to exercise deliberate practice, which has been shown to improve technical skills..$^{19,20}$ Furthermore, there is evidence to support skills transfer leading to improved performance in the operating room. ${ }^{21}$ However, technical skills are not sufficient for optimal performance and patient safety.

\section{NON-TECHNICAL SKILLS}

Non-technical skills can be divided into interpersonal (team-work, communication), cognitive (situational awareness and decision making) and personal resource skills (e.g. stress and fatigue management). ${ }^{22}$ Breakdown in these so-called 'soft-skills' remains the key root cause of near misses and patient harm in the operating room. ${ }^{5}$ They have also been shown to impact technical skills. ${ }^{23}$ Gawande and colleagues identified communication breakdown and fatigue/excessive workload accounting for $43 \%$ and $33 \%$ of incidents respectively at three teaching hospitals in USA. ${ }^{4}$

Such communication failures may occur across the entire continuum of a patient's care. ${ }^{24}$ Indeed, employment of team training programs has been associated with reduction in surgical mortality. ${ }^{25}$ Moreover, several intra-operative stressors occur in the operating room that can impair a surgeon's performance and compromise patient safety. ${ }^{26}$ Stress has been shown to impair psychomotor performance on a surgical virtual reality simulator. ${ }^{27}$

Sevdalis and colleagues demonstrated that case irrelevant communications (CICs) occur in the operating room and can interfere with sensitive work, especially during critical time points/steps of the procedure. ${ }^{26}$ Furthermore, the group correlated interference levels with the frequency of the operating room door opening. ${ }^{28}$ Noise in the theatre, which can reach 85 decibel, can lead to deterioration in the ability to communicate, increase stress levels and affect complex motor skills. ${ }^{29}$ 
Additionally, teamwork is a critical nontechnical skill that influences outcomes. Mazzocco and colleagues demonstrated that when teams demonstrated infrequent team behaviours, there was increased likelihood of death or major complications. ${ }^{30}$ This has serious implications in the operating room, especially during crisis situations where teams may be more prone to error due to poor cohesiveness and communication. ${ }^{31}$ The next section will focus on key non-technical determinants affecting patient outcomes in surgery. These include leadership and communication.

\section{LEADERSHIP}

Leadership is a fundamental non-technical skill for a surgeon. ${ }^{32-34}$ It also directly influences other non-technical skills including teamwork, with poor leadership culminating in suboptimal teamwork and compromised patient safety. ${ }^{35}$ Moreover, surgeons are expected to lead operative teams, execute multidisciplinary patient care, and engage in quality improvement. The rate at which improvements in performance are made is directly proportional to the quality of clinical leadership. ${ }^{36}$

Some surgeons also assume formal leadership positions at large institutions and healthcare organizations. ${ }^{37}$ Leadership has also been shown to impact technical skills. ${ }^{23}$ Expert surgeons believe that leadership is a critical non-technical skill that influences safety and efficiency in the operating room. ${ }^{38}$ Its inclusion in the nontechnical skills assessment rating scales, include the revised NOTECHS, further exemplifies its importance. $^{39}$

Effective leadership establishes a clear vision that is shared with individuals in an organization..$^{40}$ This is particularly pertinent for quality improvement initiatives. The optimal conditions are created for individual and organizational success and to achieve significant goals. ${ }^{41}$ Pendleton's primary colours of leadership model has three domains including (i) Strategic domain, which relies on intelligence, identifying problems and creating a vision/direction for team; (ii) Operational domain which relies on determination, executing the tasks, achieving results and (iii) Interpersonal domain, which relies on forming and sustaining relationships. ${ }^{41}$

A leader is responsible for setting a strategic direction, with clearly defined vision, values and analysis of contextual issues in an organisation. ${ }^{42}$ Quality improvement has been widely accepted as a means to enhance healthcare delivery. ${ }^{43}$ However, outside of trial settings, it has been difficult to entirely replicate the results. ${ }^{44}$ Key barriers include clinical staff engagement and the context within which the intervention takes place. These initiatives, if not aligned with strategic priorities, have limited longevity or impact. ${ }^{45}$

Alignment links the strategic domain to the interpersonal domain, relying on advocacy/ negotiating skills and building and maintaining relationships withall key stakeholders to influence change and shape organisational culture. ${ }^{46}$ This represents Burns' 'transformational leadership', distinguishing from the less potent 'transactional leadership. ${ }^{47}$

Transformational leadership stresses the importance of the relationship between the leader and the follower. It identifies the goals/ needs and exploits the intrinsic motivators of both the leader and the follower towards a shared purpose. ${ }^{48}$ This facilitates effective teamworking and is in contrast to the transactional model with the adage "You scratch my back, I scratch yours", where there is no enduring relationship and the relationship is likely to disintegrate when individual parties no longer perceive that the relationship is likely to further their own interests. ${ }^{48}$

This links with the self-determination theory (SDT), distinguishing between intrinsic and extrinsic motivators. ${ }^{49}$ Intrinsic motivators facilitate one's engagement in behaviour for its own sake, as it is personally rewarding. This contrasts extrinsic motivators, where behaviour is motivated by external rewards or to avoid punishment. ${ }^{50}$ SDT postulates three psychological needs that leaders can nurture in their followers, enhancing self-motivation and engagement.

These include autonomy (individuals obtaining increased decision making authority to execute their primary work tasks), competence (aim of mastering one's environment and outcome) and relatedness (need of close, affectionate relationships with others). ${ }^{51}$ To promote change, three key conditions as proposed by Ballard should be exploited. ${ }^{52}$ (i) Awareness of the nature of the problem to address, (ii) Alignment of objectives to the organisation's strategic priorities, and (iii) agency (ability to 
change individual and organisational mind-set, through key stakeholder buy-in). ${ }^{52}$

However, of concern, is the finding that junior surgeons underrate importance of leadership as one of the CanMEDS roles and sense that current training does not ensure competence. ${ }^{53}$ Moreover, prior research has shown that surgeons are fairly accurate at self-assessing their technical skills, but lack the insight for non-technical skills self-assessment. ${ }^{54}$

It is paramount that training program directors ensure that importance of leadership is made explicit for trainees, with adequate training and assessment, through simulation as a possible avenue and utilizing validated assessment tools. The faculty/assessors themselves would require training to ensure assessment is reliable and valid. ${ }^{55}$ This should start from undergraduate through to post-graduate training to deliver high quality surgeons who have the abilities to lead multidisciplinary clinical and academic teams, and orchestrate change.

\section{COMMUNICATION}

In Europe, the EWTD has substantially altered working patterns, continuity of care and service delivery. ${ }^{15}$ With these changes and need for patient safety, ${ }^{3}$ high quality information transfer and communication (ITC) within and between healthcare teams is paramount for safe and effective patient care. ${ }^{56}$ ITC failures are ubiquitous in surgery, occurring across the entire continuum of a patient's care and can lead to care provision errors and patient harm. ${ }^{24}$

Clinical handover is defined as transference of professional accountability and responsibility of a patient's care to another professional..$^{56}$ Effective communication is a prerequisite during this process to maintain continuity of care, and prevent errors, adverse events and patient harm..$^{57}$ A number of checklists have been shown to improve quality and completeness of surgical handover. ${ }^{58}$ However, the findings must be interpreted with caution as majority of the studies lack randomization, blinding of outcome assessors and with no adjustment for confounding factors. Moreover, there is no investigation on the impact on patient outcomes following their implementation. On the contrary, when used sub-optimally or without stakeholder buy-in, checklists can have a deleterious impact on the surgical team functionality. ${ }^{59}$
Furthermore, Ghafferi and colleagues demonstrated a 2.5 fold difference in mortality in surgical patients between hospitals with comparable post-operative complication rates, but significant differences in failure to rescue (FTR) rates (i.e. mortality amongst patients with serious complications). ${ }^{60}$ Hence, whilst complications in the post-operative period may occur, quality of care (FTR being a marker of quality) and appropriate escalation, can determine patient outcomes. ${ }^{61}$

Here the advent of ward-based simulation may provide an avenue to train, enhance and assess multidisciplinary team communication. ${ }^{62}$ Validated, reliable and feasible tools, such as the quality of information transfer (QUIT) tool, can be utilized to assess quality of information transfer during escalation of care. ${ }^{61}$ This may form part of the next frontier in simulation, i.e. full-hospital simulation across the entire patient pathway. ${ }^{63}$

This may include a simulated patient admitted to the emergency department, reviewed by the surgical resident with a decision made to proceed to the simulated operating theatre with a computer-based mannequin simulator. This can be followed by a post-operative complication in a simulated ward environment that requires prompt recognition and escalation of care. It is paramount that more robust validated assessment tools are developed and that trainers themselves are adequately trained on how to assess.

Finally, debriefing is a crucial component of Kolb's learning theory and Schon's reflective practice. ${ }^{64}$ Debriefing in surgery can decrease adverse events, enhance technical performance and facilitate deeper learning. ${ }^{65}$ It is also widely regarded as the most important component of simulation. ${ }^{64}$ However, there may be wide variation in practice. Guidelines on what constitutes an effective debrief are needed, to establish best practice and provide feedback to trainers. ${ }^{66}$

A tri-continental qualitative study established core components of an effective debrief. ${ }^{66}$ Validated, feasible and reliable tools such as the Objective Structured Assessment of Debriefing (OSAD) and feedback model, TeamGAINS have been designed to quantify debriefing quality. ${ }^{67}$ Utilization of these tools may facilitate a degree of standardization and quantification of the debriefing process to optimize surgical learning. 


\section{EVIDENCE-BASED SURGERY}

Clinical performance declines over time. ${ }^{68}$ Surgeons must demonstrate lifelong learning, contribute to scholarship and evaluate evidence. ${ }^{6}$ Evidence-based surgery is the amalgamation of the best available evidence with clinical expertise, patient and societal values. ${ }^{69}$ This facilitates rationale for decision-making and allows patients to make informed decisions. Surgeons must possess critical appraisal skills to evaluate literature for its validity, reliability and generalizability.

However, hampering this process is the lack of high quality evidence in surgery, in particular Randomized Controlled Trials (RCTs). ${ }^{70}$ Poor reporting of surgical RCTs is also problematic and ubiquitous in surgery. ${ }^{71}$ Issues related to blinding, inconsistent care provider expertise and centers' volume pose challenges both in conducting and reporting surgical RCTs, making it even more prudent that surgeons have the necessary skills to appraise such methodologies to inform their clinical practice.

The scholar domain has been described as a 'neglected competency in tomorrow's doctors. ${ }^{172}$ A survey of 515 medical students found that only $49 \%$ had understanding on how to appraise a paper and $22 \%$ had been trained on how to write a research paper. ${ }^{73}$ Reinders and colleagues showed that undergraduates who engaged in research produced four times as many publications compared to their colleagues and were more likely to pursue academia. ${ }^{74}$

However, barrierstoundertakingundergraduate research, in particular intercalated degrees, exist including cost and prolonged training time. For those universities not offering intercalated degrees inclusive of the undergraduate program, alternative measures should be in place, including journal clubs or extra-curricular evidence-based medicine (EBM) workshops. EBM teaching may also be best delivered in clinics/bedside/ward rounds, where learners can apply EBM for real decision making. ${ }^{75}$ Critical appraisal skills should be nurtured early in medical school to cultivate understanding of responsible research and to develop future surgeons who have the ability to appraise literature and exercise evidenceinformed decision making. ${ }^{76}$

\section{MENTORSHIP}

The Editor of Plastic and Reconstructive
Surgery exclaimed, "mentoring is one of the least expensive and most powerful ways to change the world." ${ }^{\prime 7}$ A mentor helps to nurture technical and non-technical skills, professional values and attitudes. There is evidence to suggest that trainees with mentors demonstrate greater productivity, experience lower rates of burnout and have improved personal satisfaction. ${ }^{78}$ The importance of mentoring is supported by both the American College of Surgeons and the RCSEng. ${ }^{79}$

Previously, as per the Halstedian apprenticeship model, one mentor-mentee relationship would last throughout the mentee's career. However, it is challenging to establish such relationships in modern practice. A national cross-sectional study of 565 UK surgical trainees revealed that $51.3 \%$ lacked a mentor. ${ }^{80}$ The rotational nature of training means trainees may rotate between different hospitals every 6-12 months, placing greater demands to establish long-term relationships, across different trusts and organizations.

Moreover, there may be no financial/other incentives for surgeons to engage in mentorship. Lack of a well-qualified mentor has also been cited as a hindrance. A mentor should be interested in the process and be willing to establish a relationship by investing time, providing guidance and constructive feedback. ${ }^{81}$ Other factors such as ethnicity, culture, religion and gender may also hinder mentoring.

However, a mentee must establish clear goals with the mentor and be responsible for their own learning. The time and commitment of mentors should also be recognized and rewarded. Ultimately, this may empower surgeons to unlock their full potential, culminating in improved outcomes. Technical skills are necessary, but not sufficient for modern surgical practice. The article has explored multiple facets of the CanMEDS framework. These are fundamental for a surgeon to develop an effective, safe and evidence-based practice that is underpinned with integrity and professionalism.

\section{CONFLICT OF INTEREST}

The authors declare no conflict of interest.

\section{REFERENCES}

1 Weiser TG, Regenbogen SE, Thompson KD, Haynes AB, Lipsitz SR, Berry WR, Gawande 
AA. An estimation of the global volume of surgery: a modelling strategy based on available data. Lancet 2008;372:139-44. doi: 10.1016/S0140-6736(08)60878-8.

2 Haynes AB, Weiser TG, Berry WR, Lipsitz SR, Breizat AH, Dellinger EP, Herbosa T, Joseph S, Kibatala PL, Lapitan MC, Merry AF, Moorthy K, Reznick RK, Taylor B, Gawande AA, Safe Surgery Saves Lives Study G. A surgical safety checklist to reduce morbidity and mortality in a global population. N Engl J Med 2009;360:491-9. doi: 10.1056/NEJMsa0810119.

3 Kohn L. To err is human: an interview with the Institute of Medicine's Linda Kohn. $J t$ Comm J Qual Improv 2000;26:227-34. doi: 10.1016/s1070-3241(00)26017-3

4 Gawande AA, Zinner MJ, Studdert DM, Brennan TA. Analysis of errors reported by surgeons at three teaching hospitals. Surgery 2003;133:614-21. doi: 10.1067/msy.2003.169.

5 Vincent C, Moorthy K, Sarker SK, Chang A, Darzi AW. Systems approaches to surgical quality and safety: from concept to measurement. Ann Surg 2004;239:475-82. doi: 10.1097/01.sla.0000118753.22830.41.

6 Frank JR, Danoff D. The CanMEDS initiative: implementing an outcomes-based framework of physician competencies. Med Teach 2007;29:642-7. doi: 10.1080/01421590701746983.

7 Moorthy K, Munz Y, Sarker SK, Darzi A. Objective assessment of technical skills in surgery. BMJ 2003;327:1032-7. doi: 10.1136/ bmj.327.7422.1032.

8 Mahmoudi E, Lu Y, Chang SC, Lin CY, Wang YC, Chang CJ, Cheng MH, Chung KC. The Associations of Hospital Volume, Surgeon Volume, and Surgeon Experience with Complications and 30Day Rehospitalization after Free Tissue Transfer: A National Population Study. Plast Reconstr Surg 2017;140:403-11. doi: 10.1097/ PRS.0000000000003515.

9 Birkmeyer JD, Siewers AE, Finlayson EV, Stukel TA, Lucas FL, Batista I, Welch HG, Wennberg DE. Hospital volume and surgical mortality in the United States. $N$ Engl J Med 2002;346:1128-37. doi: 10.1056/ NEJMsa012337.

10 Luft HS, Bunker JP, Enthoven AC. Should operations be regionalized? The empirical relation between surgical volume and mortality. N Engl J Med 1979;301:1364-9. doi: 10.1056/NEJM197912203012503.

11 Trinh QD, Bjartell A, Freedland SJ, Hollenbeck BK, Hu JC, Shariat SF, Sun M, Vickers AJ. A systematic review of the volume-outcome relationship for radical prostatectomy. Eur Urol 2013;64:786-98. doi: 10.1016/j.eururo.2013.04.012.

12 Kneebone R, Aggarwal R. Surgical training using simulation. BMJ 2009;338:b1001. doi: 10.1136/bmj.b1001.

13 Royston CM, Lansdown MR, Brough WA. Teaching laparoscopic surgery: the need for guidelines. $B M J$ 1994;308:1023-5. doi: 10.1136/bmj.308.6935.1023.

14 Cuschieri A. Whither minimal access surgery: tribulations and expectations. $\mathrm{Am}$ J Surg 1995;169:9-19. doi: 10.1016/s00029610(99)80104-4.

15 Canter R. Impact of reduced working time on surgical training in the United Kingdom and Ireland. Surgeon 2011;9 Suppl 1:S6-7. doi: 10.1016/j.surge.2010.11.020.

16 Arora S, Aggarwal R, Sirimanna P, Moran A, Grantcharov T, Kneebone R, Sevdalis N, Darzi A. Mental practice enhances surgical technical skills: a randomized controlled study. Ann Surg 2011;253:265-70. doi: 10.1097/ SLA.0b013e318207a789.

17 Aggarwal R, Grantcharov TP, Eriksen JR, Blirup D, Kristiansen VB, Funch-Jensen P, Darzi A. An evidence-based virtual reality training program for novice laparoscopic surgeons. Ann Surg 2006;244:310-4. doi: 10.1097/01.sla.0000218094.92650.44.

18 van Hove PD, Tuijthof GJ, Verdaasdonk EG, Stassen LP, Dankelman J. Objective assessment of technical surgical skills. $\mathrm{Br} J$ Surg 2010;97:972-87. doi: 10.1002/bjs.7115.

19 Crochet P, Aggarwal R, Dubb SS, Ziprin P, Rajaretnam N, Grantcharov T, Ericsson KA, Darzi A. Deliberate practice on a virtual reality laparoscopic simulator enhances the quality of surgical technical skills. Ann Surg 2011;253:1216-22. doi: 10.1097/ SLA.0b013e3182197016.

20 Kotsis SV, Chung KC. Application of the "see one, do one, teach one" concept in surgical training. Plast Reconstr Surg 2013;131:1194201. doi: 10.1097/PRS.0b013e318287a0b3.

21 Grantcharov TP, Kristiansen VB, Bendix J, Bardram L, Rosenberg J, Funch-Jensen P. Randomized clinical trial of virtual reality 
simulation for laparoscopic skills training. $\mathrm{Br}$ J Surg 2004;91:146-50. doi: 10.1002/bjs.4407.

22 Flin R, Yule S, Paterson-Brown S, Maran N, Rowley D, Youngson G. Teaching surgeons about non-technical skills. Surgeon 2007;5:869. doi: 10.1016/s1479-666x(07)80059-x.

23 Hull L, Arora S, Aggarwal R, Darzi A, Vincent C, Sevdalis N. The impact of nontechnical skills on technical performance in surgery: a systematic review. $J \mathrm{Am}$ Coll Surg 2012;214:214-30. doi: 10.1016/j. jamcollsurg.2011.10.016.

24 Nagpal K, Arora S, Vats A, Wong HW, Sevdalis N, Vincent C, Moorthy K. Failures in communication and information transfer across the surgical care pathway: interview study. BMJ Qual Saf 2012;21:843-9. doi: 10.1136/bmjqs-2012-000886.

25 Neily J, Mills PD, Young-Xu Y, Carney BT, West P, Berger DH, Mazzia LM, Paull DE, Bagian JP. Association between implementation of a medical team training program and surgical mortality. JAMA 2010;304:1693-700. doi: 10.1001/jama.2010.1506.

26 Sevdalis N, Healey AN, Vincent CA. Distracting communications in the operating theatre. J Eval Clin Pract 2007;13:390-4. doi: 10.1111/j.1365-2753.2006.00712.x.

27 Arora S, Sevdalis N, Aggarwal R, Sirimanna P, Darzi A, Kneebone R. Stress impairs psychomotor performance in novice laparoscopic surgeons. Surg Endosc 2010;24:2588-93. doi: 10.1007/s00464-0101013-2.

28 Healey AN, Sevdalis N, Vincent CA. Measuring intra-operative interference from distraction and interruption observed in the operating theatre. Ergonomics 2006;49:589604. doi: 10.1080/00140130600568899.

29 Mentis HM, Chellali A, Manser K, Cao CG, Schwaitzberg SD. A systematic review of the effect of distraction on surgeon performance: directions for operating room policy and surgical training. Surg Endosc 2016;30:171324. doi: 10.1007/s00464-015-4443-z.

30 Mazzocco K, Petitti DB, Fong KT, Bonacum D, Brookey J, Graham S, Lasky RE, Sexton JB, Thomas EJ. Surgical team behaviors and patient outcomes. Am J Surg 2009;197:678-85. doi: 10.1016/j.amjsurg.2008.03.002.

31 Undre S, Sevdalis N, Healey AN, Darzi S, Vincent CA. Teamwork in the operating theatre: cohesion or confusion? J Eval Clin
Pract 2006;12:182-9. doi: 10.1111/j.13652753.2006.00614.x.

32 Angood P, Birk S. The value of physician leadership. Physician Exec 2014;40:6-20.

33 Henrickson Parker S, Yule S, Flin R, McKinley A. Towards a model of surgeons' leadership in the operating room. BMJ Qual Saf 2011;20:570-9. doi: 10.1136/ bmjqs.2010.040295.

34 Verheyden CN, Levin LS. Plastic surgery leadership in an institution: a primer. Plast Reconstr Surg 2010;125:1819-25. doi: 10.1097/ PRS.0b013e3181d0ab39.

35 Zaccaro SJ, Rittman AL, Marks MA. Team leadership. The Leadership Quarterly 2001;12:451-83.

36 Berwick DM. Improvement, trust, and the healthcare workforce. Qual Saf Health Care 2003;12:448-52. doi: 10.1136/qhc.12.6.448.

37 Pradarelli JC, Jaffe GA, Lemak CH, Mulholland MW, Dimick JB. A leadership development program for surgeons: First-year participant evaluation. Surgery 2016;160:25563. doi: 10.1016/j.surg.2016.03.011.

38 Yule S, Flin R, Paterson-Brown S, Maran N. Non-technical skills for surgeons in the operating room: a review of the literature. Surgery 2006;139:140-9. doi: 10.1016/j. surg.2005.06.017.

39 Sevdalis N, Davis R, Koutantji M, Undre S, Darzi A, Vincent CA. Reliability of a revised NOTECHS scale for use in surgical teams. Am J Surg 2008;196:184-90. doi: 10.1016/j. amjsurg.2007.08.070.

40 Maykel JA. Leadership in surgery. Clin Colon Rectal Surg 2013;26:254-8. doi: 10.1055/s0033-1356727.

41 Pendleton D. Leadership for primary health care research. Prim Health Care Res Dev 2012;13:301-7. doi: 10.1017/ S1463423612000485.

42 Souba WW. Leadership and strategic alignment--getting people on board and engaged. J Surg Res 2001;96:144-51. doi: 10.1006/jsre.2001.6118.

43 Pannick S, Sevdalis N, Athanasiou T. Beyond clinical engagement: a pragmatic model for quality improvement interventions, aligning clinical and managerial priorities. BMJ Qual Saf 2016;25:716-25. doi: 10.1136/ bmjqs-2015-004453.

44 Haugen AS, Softeland E, Almeland SK, Sevdalis N, Vonen B, Eide GE, Nortvedt 
MW, Harthug S. Effect of the World Health Organization checklist on patient outcomes: a stepped wedge cluster randomized controlled trial. Ann Surg 2015;261:821-8. doi: 10.1097/ SLA.0000000000000716.

45 Morgan L, New S, Robertson E, Collins G, Rivero-Arias O, Catchpole K, Pickering SP, Hadi M, Griffin D, McCulloch P. Effectiveness of facilitated introduction of a standard operating procedure into routine processes in the operating theatre: a controlled interrupted time series. BMJ Qual Saf 2015;24:120-7. doi: 10.1136/bmjqs-2014-003158.

46 Kumar S, Kumar N, Adhish VS, Reddy RS. Strategic Management and Leadership for Health Professionals - Skills To Leverage Resources To Achieve Health Goals. Indian J Community Med 2015;40:158-62. doi: 10.4103/0970-0218.158845.

47 Pasalar M, Mohammadi AA, Rajaeefard A, Neghab M, Tolidie H, Mehrabani D. Epidemiology of burns during pregnancy in southern Iran: Effect on maternal and fetal outcomes. World Appl Sci J 2013;28:153-8.

48 Tremaine M. Women mayors say what it takes to lead: Setting theory against lived experience. Women in Management Review 2000;15:246-52.

49 Ryan RM, Deci EL. Self-determination theory and the facilitation of intrinsic motivation, social development, and well-being. $\mathrm{Am}$ Psychol 2000;55:68-78. doi: 10.1037//0003066x.55.1.68.

50 Patrick H, Williams GC. Self-determination theory: its application to health behavior and complementarity with motivational interviewing. Int J Behav Nutr Phys Act 2012;9:18. doi: 10.1186/1479-5868-9-18.

51 Leach DJ, Wall TD, Jackson PR. The effect of empowerment on job knowledge: An empirical test involving operators of complex technology. J Occup Organ Psychol 2003;76:27-52.

52 Ballard D. Using learning processes to promote change for sustainable development. Action research 2005;3:135-56.

53 Arora S, Sevdalis N, Suliman I, Athanasiou T, Kneebone R, Darzi A. What makes a competent surgeon?: experts' and trainees' perceptions of the roles of a surgeon. Am J Surg 2009;198:726-32. doi: 10.1016/j. amjsurg.2009.01.015.

54 Arora S, Miskovic D, Hull L, Moorthy K,
Aggarwal R, Johannsson H, Gautama S, Kneebone R, Sevdalis N. Self vs expert assessment of technical and non-technical skills in high fidelity simulation. $\mathrm{Am}$ J Surg 2011;202:500-6. doi: 10.1016/j. amjsurg.2011.01.024.

55 Hull L, Arora S, Symons NR, Jalil R, Darzi A, Vincent C, Sevdalis N, Delphi Expert Consensus P. Training faculty in nontechnical skill assessment: national guidelines on program requirements. Ann Surg 2013;258:370-5. doi: 10.1097/ SLA.0b013e318279560b.

56 Nagpal K, Arora S, Abboudi M, Vats A, Wong HW, Manchanda C, Vincent C, Moorthy K. Postoperative handover: problems, pitfalls, and prevention of error. Ann Surg 2010;252:171-6. doi: 10.1097/SLA.0b013e3181dc3656.

57 Symons NR, Almoudaris AM, Nagpal K, Vincent CA, Moorthy K. An observational study of the frequency, severity, and etiology of failures in postoperative care after major elective general surgery. Ann Surg 2013;257:15. doi: 10.1097/SLA.0b013e31826d859b.

58 Pucher PH, Johnston MJ, Aggarwal R, Arora S, Darzi A. Effectiveness of interventions to improve patient handover in surgery: A systematic review. Surgery 2015;158:85-95. doi: 10.1016/j.surg.2015.02.017.

59 Russ S, Rout S, Sevdalis N, Moorthy K, Darzi A, Vincent C. Do safety checklists improve teamwork and communication in the operating room? A systematic review. Ann Surg 2013;258:856-71. doi: 10.1097/ SLA.0000000000000206.

60 Ghaferi AA, Birkmeyer JD, Dimick JB. Complications, failure to rescue, and mortality with major inpatient surgery in medicare patients. Ann Surg 2009;250:1029-34. doi: 10.1097/sla.0b013e3181bef697.

61 Johnston MJ, Arora S, Pucher PH, Reissis Y, Hull L, Huddy JR, King D, Darzi A. Improving Escalation of Care: Development and Validation of the Quality of Information Transfer Tool. Ann Surg 2016;263:477-86. doi: 10.1097/SLA.0000000000001164.

62 Pucher PH, Aggarwal R, Singh P, Srisatkunam T, Twaij A, Darzi A. Ward simulation to improve surgical ward round performance: a randomized controlled trial of a simulationbased curriculum. Ann Surg 2014;260:236-43. doi: 10.1097/SLA.0000000000000557.

63 Arora S, Cox C, Davies S, Kassab E, Mahoney 
P, Sharma E, Darzi A, Vincent C, Sevdalis N. Towards the next frontier for simulation-based training: full-hospital simulation across the entire patient pathway. Ann Surg 2014;260:2528. doi: 10.1097/SLA.0000000000000305.

64 Johnston MJ, Paige JT, Aggarwal R, Stefanidis D, Tsuda S, Khajuria A, Arora S, Association for Surgical Education Simulation C. An overview of research priorities in surgical simulation: what the literature shows has been achieved during the 21st century and what remains. Am J Surg 2016;211:214-25. doi: 10.1016/j.amjsurg.2015.06.014.

65 Mahmood T, Darzi A. The learning curve for a colonoscopy simulator in the absence of any feedback: no feedback, no learning. Surg Endosc 2004;18:1224-30. doi: 10.1007/ s00464-003-9143-4.

66 Ahmed M, Sevdalis N, Paige J, ParagiGururaja R, Nestel D, Arora S. Identifying best practice guidelines for debriefing in surgery: a tri-continental study. Am J Surg 2012;203:5239. doi: 10.1016/j.amjsurg.2011.09.024.

67 Arora S, Ahmed M, Paige J, Nestel D, Runnacles J, Hull L, Darzi A, Sevdalis N. Objective structured assessment of debriefing: bringing science to the art of debriefing in surgery. Ann Surg 2012;256:982-8. doi: 10.1097/SLA.0b013e3182610c91.

68 Choudhry NK, Fletcher RH, Soumerai SB. Systematic review: the relationship between clinical experience and quality of health care. Ann Intern Med 2005;142:260-73. doi: 10.7326/0003-4819-142-4-200502150-00008.

69 Garas G, Ibrahim A, Ashrafian H, Ahmed K, Patel V, Okabayashi K, Skapinakis P, Darzi A, Athanasiou T. Evidence-based surgery: barriers, solutions, and the role of evidence synthesis. World J Surg 2012;36:1723-31. doi: 10.1007/s00268-012-1597-x.

70 Khajuria A, Agha RA. Surgical clinical trials--need for quantity and quality. Lancet 2013;382:1876. doi: 10.1016/S01406736(13)62620-3.

71 Khajuria A, Ahmed Agha R. CONSORT compliance in surgical randomized trials: possible solutions. Ann Surg 2015;261:e135. doi: 10.1097/SLA.0000000000000409.

72 Ologunde R, Di Salvo I, Khajuria A. The CanMEDS scholar: the neglected competency in tomorrow's doctors. Adv Med Educ Pract 2014;5:383-4. doi: 10.2147/AMEP.S71763.

73 Griffin MF, Hindocha S. Publication practices of medical students at British medical schools: experience, attitudes and barriers to publish. Med Teach 2011;33:e1-8. doi: 10.3109/0142159X.2011.530320.

74 Reinders JJ, Kropmans TJ, Cohen-Schotanus J. Extracurricular research experience of medical students and their scientific output after graduation. Med Educ 2005;39:237. doi: 10.1111/j.1365-2929.2004.02078.x.

75 Welch HG, Lurie JD. Teaching evidencebased medicine: caveats and challenges. Acad Med 2000;75:235-40. doi: 10.1097/00001888200003000-00010.

76 Khajuria A, Agha R. Fraud in scientific research - birth of the Concordat to uphold research integrity in the United Kingdom. J R Soc Med 2014;107:61-5. doi: 10.1177/0141076813511452.

77 Rohrich RJ. Mentors in medicine. Plast Reconstr Surg 2003;112:1087-8. doi: 10.1097/01.PRS.0000080319.87331.9F.

78 Wilkes M, Feldman MD. Mentoring clinical trainees: a need for high touch. Lancet 2017;389:135-7. doi: 10.1016/S01406736(16)32571-5.

79 RCSEng. Mentoring - A Guide to Good Practice 2015. [Accessed 27 June 2019]. Available from: https://www.rcseng.ac.uk/ library-and-publications/rcs-publications/ docs/mentoring-good-practice

80 Sinclair P, Fitzgerald JE, Hornby ST, Shalhoub J. Mentorship in surgical training: current status and a needs assessment for future mentoring programs in surgery. World J Surg 2015;39:303-13; discussion 14. doi: 10.1007/ s00268-014-2774-x.

81 Patel VM, Warren O, Ahmed K, Humphris P, Abbasi S, Ashrafian H, Darzi A, Athanasiou T. How can we build mentorship in surgeons of the future? ANZ J Surg 2011;81:418-24. doi: 10.1111/j.1445-2197.2011.05779.x. 